\title{
Prospective Study of BK Virus Infection in Patients with Inflammatory Bowel Disease
}

\author{
Virginia Flores, ${ }^{1,2}$ Belén Rodríguez-Sánchez, ${ }^{3,4}$ Ignacio Marín-Jiménez, ${ }^{1,2}$ \\ Emilio Bouza, ${ }^{3,4,5,6}$ Luis Menchén, ${ }^{1,2}$ and Patricia Muñoz ${ }^{3,4,6}$ \\ ${ }^{1}$ Department of Digestive Diseases, General University Hospital Gregorio Marañón, Dr. Esquerdo 46, 28007 Madrid, Spain \\ ${ }^{2}$ CIBER Hepatic and Digestive Diseases (CIBEREHD), 07110 Bunyola, Balearic Islands, Spain \\ ${ }^{3}$ Department of Clinical Microbiology and Infectious Diseases, General University Hospital Gregorio Marañón, \\ Dr. Esquerdo 46, 28007 Madrid, Spain \\ ${ }^{4}$ CIBER Respiratory Diseases (CIBERES CB06/06/0058), 07110 Bunyola, Balearic Islands, Spain \\ ${ }^{5}$ Department of Medicine, Faculty of Medicine, Complutense University of Madrid, 28040 Madrid, Spain \\ ${ }^{6}$ Spanish Study Group on Infection in Transplant Recipients (GESITRA-RESITRA-REIPI), RD06/0008/1025, Spain
}

Correspondence should be addressed to Patricia Muñoz; pmunoz@micro.hggm.es

Received 11 November 2013; Accepted 24 December 2013; Published 13 February 2014

Academic Editors: D. P. Levine and A. Zakhartchouk

Copyright (C) 2014 Virginia Flores et al. This is an open access article distributed under the Creative Commons Attribution License, which permits unrestricted use, distribution, and reproduction in any medium, provided the original work is properly cited.

\begin{abstract}
Patients with inflammatory bowel disease (IBD) have an immune-deficient baseline status further modulated by immunosuppressive therapy that may promote the reactivation of latent viruses such as BK virus (BKV). The aim of this prospective study was to determine the prevalence of BKV infection in IBD patients and its potential relationship with the immunosuppressive treatment. Paired urine and plasma samples from 53 consecutive patients with IBD and 53 controls were analyzed. BKV detection was performed by conventional PCR and positive samples were further quantified by real-time PCR. No viremia was detected. BKV viruria was significantly more common in IBD patients than among the controls $(54.7 \%$ versus $11.3 \%$; $P<0.0001)$. The only risk factor for BKV viruria in IBD was age $(47.2 \pm 16.3$ versus $37.8 \pm 15.2 ; P=0.036)$, and there was a trend towards higher rate of viruria in outpatients $(61.5 \%$ versus $38.5 \% ; P=0.096)$ and in those not receiving ciprofloxacin $(59.5 \%$ versus $40.5 \% ; P=0.17)$. A clear impact of the immunosuppressive regimen on BKV infection could not be demonstrated.
\end{abstract}

\section{Introduction}

Human polyomavirus $\mathrm{BK}(\mathrm{BKV})$ is a double-stranded DNA virus with a small circular genome. It belongs to the Polyomaviridae family, which includes JC virus, Simian Virus 40 (SV40), and Merkel cell polyomavirus [1,2]. These viruses are very similar in structure, with high DNA sequence homology and an icosahedral capsid.

More than $80 \%$ of the world's population has serological evidence of exposure to BKV [3]. Primary infection typically takes place during childhood, with no specific symptoms, and the virus remains latent for life, mainly in urothelial cells [4]. The natural route of transmission has not been clearly defined and may be oral or respiratory. The virus has been isolated in urine, plasma, and biopsy specimens such as kidney, liver, eye, and brain [5]. Under immunosuppressive conditions, BKV can reactivate and cause disease. This is common in kidney recipients and AIDS patients, in whom BKV may cause renal failure due to severe acute interstitial nephritis, meningoencephalitis, pneumonitis, and retinitis [5, 6]. In hematopoietic stem cell recipients the most common manifestation of BKV is hemorrhagic cystitis [7]. Besides these direct effects, an oncogenic potential has been reported in patients with colorectal cancer [8]. Regarding gastrointestinal manifestations, a case of colonic ulceration associated with BKV has been published [9]. Its role in other immunocompromised populations has not been elucidated.

In this study, we analyze the prevalence of BKV infection in patients with inflammatory bowel disease (IBD), a condition that has not previously been related to BKV. We also 
analyze the potential relationship between BKV infection and the different immunosuppressive regimens used in this population.

\section{Material and Methods}

2.1. Patients. We performed a prospective study in 53 consecutive unselected IBD patients (inpatients and outpatients) who attended consecutively in the Digestive Medicine Department between April 2008 and May 2012. Patients were admitted to hospital for exacerbation of their disease or attended in the day-hospital for clinical follow-up. Plasma and urine samples from 53 healthy volunteers, matched by age and gender, were also included as a control group.

Using a preestablished form, the same trained physicians collected epidemiological and clinical data from all patients as follows: IBD activity and extension, clinical characteristics, family and personal history, age at diagnosis, perianal disease, need for surgery, renal insufficiency, extraintestinal disease, and previous and current therapy. Ciprofloxacin was administered to patients with acute outbreaks due to exacerbation of their disease. This antibiotic was chosen for its anti-inflammatory effect on the intestinal mucosa and to prevent bacterial overinfections.

The severity of the underlying disease was classified according to standard definitions, including the HarveyBradshaw index and the Montreal classification for inflammatory bowel diseases $[10,11]$. For analytical purposes, we considered as "severe" the forms classified as such with the Harvey Bradshaw index for Crohn's disease and as S3 for those with ulcerative colitis.

Renal function was assessed using plasma creatinine levels and glomerular filtration rate (GFR) determined using the MDRD equation. Renal impairment was defined as the increase in the serum creatinine $\times 2$. Microscopic hematuria was defined as the presence of $\geq 3$ RBCs per high-power field in at least 2 specimens of unspun urine. Pyuria was described as $>3 \mathrm{WBC} / \mathrm{hpf}$ unspun urine or positive leukocyte esterase.

$\mathrm{BKV}$ infection was defined as the evidence of virus exposure reflected by the PCR detection of virus in blood or urine samples. BKV disease was defined as the histopathological or ultrastructural evidence of cytopathic and organic damage caused by this virus [3].

The local ethics committee approved the study and all patients gave their informed consent.

\subsection{Nested and Quantitative Real-Time Polymerase Chain} Reaction (PCR). Simultaneous urine and plasma samples were collected for detection of BKV. All samples were aliquoted and frozen at $-20^{\circ} \mathrm{C}$ prior to analysis. DNA was extracted using the QIAamp viral DNA mini kit (Qiagen, Hilden, Germany) and stored frozen at $-70^{\circ} \mathrm{C}$ before use. DNA samples were screened for BKV using a nested PCR assay, which amplified a specific region of the BKV large Tantigen [12]. The methodology of this PCR assay is addressed in detail elsewhere [13-15].

Positive samples were quantified using LightCycler chemistry (Roche Diagnostics, Mannheim, Germany) according to a previously described real-time assay based on a region of BKV VP1 (detection limit, 100 copies/mL) [16]. Known concentrations of the plasmid pB-VP1 containing the amplified $\mathrm{BKV}$ region (kindly provided by Professor Kwong from the University Hospital of Hong Kong) were used to obtain a standard curve for quantification.

2.3. Statistical Analysis. The characteristics of patients with and without BKV infection were analyzed. Normally distributed quantitative variables were compared using a $t$-test and mean results with standard deviation were provided; nonnormally distributed variables were compared using the Mann-Whitney $U$ test. Normal distribution was analyzed with the Kolmogorov-Smirnov test. Qualitative variables were compared using the Fisher exact test. All $P$ values were based on a 2 -tailed test of significance $(P<0.05)$. Statistical analysis was performed with SPSS version 15.0.

\section{Results}

3.1. Study Population. The study sample comprised 53 patients with IBD. The underlying conditions consisted of Crohn's disease $(32,60.4 \%)$ and ulcerative colitis $(21,39.6 \%)$. The mean age of the patients was $42.92 \pm 16.34$ years (median 33 years, $15-72$ ), and $49.1 \%$ were men.

The classification of the severity of the underlying diseases is shown in Table 1. Forty-six patients had moderate disease $(86.8 \%)$ according to the Harvey-Bradshaw index and the Montreal classifications $[10,11]$. Fourteen patients were on an acute exacerbation episode and were hospitalized, and the remaining thirty-nine were outpatients on chronic follow-up (Table 2).

Regarding immunosuppressive therapy, 12 (22.6\%) patients were not receiving any immunosuppressive agent since they were in remission. The remaining $41(77.4 \%)$ received infliximab/adalimumab, 24 patients; azathioprine, 9 patients; and systemic corticosteroids, 8 patients.

Renal function was normal (mean creatinine, $0.80 \pm$ $0.18 \mathrm{mg} / \mathrm{dL}$; median $0.8,0.5-1.4$ ) in all but 1 patient who fulfilled our criteria for renal insufficiency. This patient had leftsided nonsevere ulcerative colitis (treated with azathioprine) and presented BK viruria, although with a low viral load (100 copies/mL). No relationship between BKV infection and renal function parameters was found in this population.

3.2. BKV Prevalence and Viral Load. None of the IBD patients developed viremia. The prevalence of BKV viruria was significantly higher in the study group than in the control group (29 IBD patients-54.7\%-versus 6 healthy volunteers$11.3 \%-; P<0.0001)$.

When IBD patients with and without viruria were compared, higher rates were observed in older patients (47.2 \pm 16.3 years versus $37.8 \pm 15.2$ in nonviruric; $P=0.036$ ). A trend towards a more frequent $\mathrm{BKV}$ viruria was found in patients not receiving ciprofloxacin (59.5\% versus $40.5 \%$, $P=0.17)$ and in outpatients $(61.5 \%$ versus $38.5 \% ; P=0.096)$. Outpatients received less frequently systemic corticosteroids (16.7\% versus $57.1 \% ; P=0.095$ ). 
TABLE 1: Severity of the inflammatory bowel disease of the 53 patients included in the study according to the Harvey Bradshaw index and the Montreal classification.

(a) Patients with Crohn's disease $(n=32)$

\begin{tabular}{lcccc}
\hline Age at diagnosis & Location & Behavior & Perianal disease & Harvey bradshaw \\
\hline A1: $3(9.4 \%)$ & L1: $8(25.0 \%)$ & B1: $13(40.6 \%)$ & No: $21(65.6 \%)$ & Remission: $8(25.0 \%)$ \\
A2: $24(75.0 \%)$ & L2: $8(25.0 \%)$ & B2: $8(25.0 \%)$ & Yes: $11(34.4 \%)$ & Mild: $9(28.1 \%)$ \\
A3: $5(15.6 \%)$ & L3: $15(46.8 \%)$ & B3: $11(34.4 \%)$ & & Moderate: $10(31.2 \%)$ \\
& L4: $1(3.2 \%)$ & & & Severe: $5(15.7 \%)$ \\
\hline
\end{tabular}

(b) Patients with ulcerative colitis $(n=21)$

\begin{tabular}{lc}
\hline Extension & Severity \\
\hline E1: $5(23.8 \%)$ & S0: $5(23.8 \%)$ \\
E2: $7(33.3 \%)$ & S1: $6(28.6 \%)$ \\
E3: $9(42.9 \%)$ & S2: $8(38.1 \%)$ \\
& S3:2(9.5\%) \\
\hline
\end{tabular}

A1: below 16 y; A2: 17-40 y; A3: above $40 \mathrm{y}$.

L1: ileal; L2: colonic; L3: ileocolonic; L4: isolated upper disease.

B1: nonstricturing, nonpenetrating; B2: stricturing; B3: penetrating.

E1: ulcerative proctitis. Involvement limited to the rectum.

E2: left-sided ulcerative colitis. Involvement limited to a proportion of the colorectum distal to the splenic flexure.

E3: extensive pancolitis. Involvement extends proximally to the splenic flexure.

S1: mild colitis; S2: moderate colitis; S3: severe colitis.

TABLE 2: Comparison of inflammatory bowel disease patients with and without BKV viruria.

\begin{tabular}{|c|c|c|c|c|}
\hline & $\begin{array}{l}\text { All patients } \\
\qquad N=53\end{array}$ & $\begin{array}{c}\text { Viruric patients } \\
\qquad N=29\end{array}$ & $\begin{array}{c}\text { Nonviruric patients } \\
\qquad N=24\end{array}$ & $P$ value \\
\hline Age $($ mean $\pm S D)$ & $42.92 \pm 16.34$ & $47.2 \pm 16.3$ & $37.8 \pm 15.2$ & 0.036 \\
\hline Males (\%) & $26(49.1)$ & $12(46.2)$ & $14(53.8)$ & 0.217 \\
\hline \multicolumn{5}{|l|}{ Type of IBD } \\
\hline Crohn's disease (\%) & $32(60.4)$ & $17(53.1)$ & $15(46.9)$ & \multirow{2}{*}{0.610} \\
\hline Ulcerative colitis (\%) & $21(39.6)$ & $12(57.1)$ & $9(42.9)$ & \\
\hline Previous surgery (\%) & $18(34.0)$ & $8(44.4)$ & $10(55.6)$ & 0.930 \\
\hline \multicolumn{5}{|l|}{ Severity of IBD } \\
\hline Severe & $7(13.2)$ & $4(57.1)$ & $3(42.9)$ & \multirow{2}{*}{0.890} \\
\hline Nonsevere & $46(86.8)$ & $25(54.3)$ & $21(45.7)$ & \\
\hline \multicolumn{5}{|l|}{ Hospital admission at inclusion (\%) } \\
\hline No & $39(73.6)$ & $24(61.5)$ & $15(38.5)$ & \multirow{2}{*}{0.096} \\
\hline Yes & $14(26.4)$ & $5(35.7)$ & $9(64.3)$ & \\
\hline \multicolumn{5}{|l|}{ Immunosuppressive therapy (\%) } \\
\hline No & $12(22.6)$ & $5(41.7)$ & $7(58.3)$ & \multirow{2}{*}{0.302} \\
\hline Yes & $41(77.4)$ & $24(58.5)$ & $17(41.5)$ & \\
\hline \multicolumn{5}{|l|}{ Infliximab/adalimumab } \\
\hline No & $29(54.7)$ & $15(51.7)$ & $14(48.3)$ & \multirow{2}{*}{0.630} \\
\hline Yes & $24(45.3)$ & $14(58.3)$ & $10(41.7)$ & \\
\hline \multicolumn{5}{|l|}{ Systemic corticosteroids } \\
\hline No & $45(84.9)$ & $23(51.1)$ & $22(48.9)$ & \multirow{2}{*}{0.771} \\
\hline Yes & $8(15.1)$ & $6(75)$ & $2(25)$ & \\
\hline Serum creatinine $(\mathrm{mg} / \mathrm{dL}$, mean $\pm \mathrm{SD})$ & $0.80 \pm 0.18$ & $0.82 \pm 0.14$ & $0.78 \pm 0.2$ & 0.411 \\
\hline \multicolumn{5}{|l|}{ Ciprofloxacin at inclusion } \\
\hline No & $42(79.2)$ & $25(59.5)$ & $17(40.5)$ & \multirow{2}{*}{0.170} \\
\hline Yes & $11(20.8)$ & $4(36.4)$ & $7(63.6)$ & \\
\hline \multicolumn{5}{|l|}{ Urinalysis } \\
\hline Hematuria & $6(11.3)$ & $4(13.8)$ & $2(8.3)$ & 0.532 \\
\hline Leukocyturia & $8(15.1)$ & $5(17.2)$ & $3(12.5)$ & 0.631 \\
\hline
\end{tabular}

Statistically significant $P$ values are shown in bold. 
TABLE 3: BKV viral loads in the $29 \mathrm{BKV}$ viruric patients with inflammatory bowel disease.

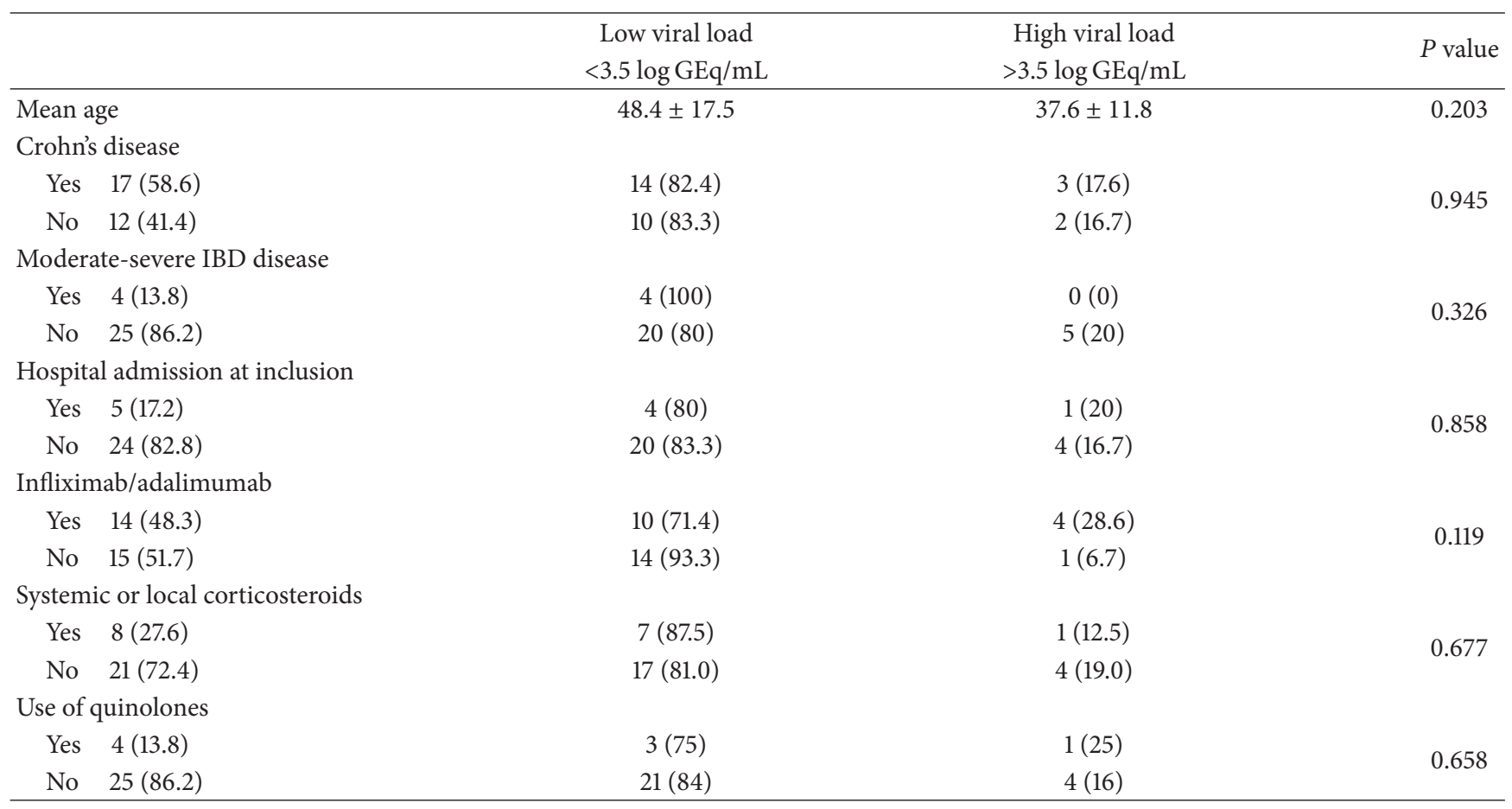

We could not find a relationship between BKV viruria and the underlying disease (Crohn's disease versus ulcerative colitis; $P=0.610)$, the severity of the IBD disease $(P=$ $0.890)$, previous surgery $(P=0.930)$, or treatment with an immunosuppressive $\operatorname{drug}(P=0.302)$ (Table 2$)$.

The median viral load of viruric patients was $2 \log 10$ genome equivalents $(\mathrm{GEq}) / \mathrm{mL} \quad(25$ th percentiles = $2 \log 10 \mathrm{GEq} / \mathrm{mL}$, 75th percentile $=5 \log 10 \mathrm{GEq} / \mathrm{mL})$. A high viral load, defined as $3.5 \mathrm{GEq} / \mathrm{mL}$ [17], was detected in 5 patients (median 5, $2 \log 10 \mathrm{GEq} / \mathrm{mL}$ ). High viral load was more frequent in younger patients (mean age $37.6 \pm 11.8$ years versus $48.4 \pm 17.5$ years; $P=0.203$ ) and in patients receiving monoclonal therapy $(28.6 \%$ versus $6.7 \% ; P=0.119)$ (Table 3).

\section{Discussion}

This is the first study on BKV infection in patients with IBD. We observed that $54.7 \%$ of IBD patients were viruric, a significantly higher frequency than a control population, although a relationship with attributable clinical manifestations could not be established.

The frequency of BKV viruria in IBD is higher than the rate expected for the age range of the study population [17]. It could be explained by the baseline immunosuppressive status of patients with IBD and by the use of immunosuppressive drugs necessary for the treatment of the illness. $41.7 \%$ of viruric patients were not receiving any immunosuppressive agent, while $58.3 \%$ were receiving anti-TNF treatment. In addition, BKV viral load tended to be higher in patients receiving infliximab/adalimumab $(5 \log 10 \mathrm{GEq} / \mathrm{mL}$ versus 3 , 5log10 GEq, $P=0.119$ ), although no statistical significance was reached probably due to the limited number of patients with high viral load.

Some monoclonal antibodies have been demonstrated to reactivate polyomaviruses. Severe forms of progressive multifocal leukoencephalopathy due to JCV, another Polyomavirus, have been described in multiple sclerosis patients treated with the humanized monoclonal anti-alpha- 4 integrin antibody, natalizumab, and 5 cases of BKV CSF infection $[18,19]$. Asymptomatic reactivation of $\mathrm{BKV}$ has also been described in patients with multiple sclerosis treated with natalizumab and the frequency of BKV viruria increased with the number of doses of natalizumab received (mean, 11.2 doses) [20]. However, we could not demonstrate a similar relationship of infliximab/adalimumab with BKV, and none of our patients developed attributable neurological manifestations.

In our series, BKV infection was not associated with the severity of IBD. In fact, BKV infection was more prevalent in outpatients, who had less severe disease and were receiving less frequently corticosteroids (16.7\% versus $57.1 \%, P=$ $0.095)$ and ciprofloxacin (59.5\% versus $40.5 \%, P=0.17)$. Ciprofloxacin has been associated with lower rates of $\mathrm{BK}$ viremia in renal transplant and hematopoietic transplant recipients [21-23]. This is due to its capacity to inhibit the polyomavirus large T-antigen helicase [24]. In our study, IBD patients that were receiving ciprofloxacin were less prone to have an infection caused by BKV (36.4\% versus 63.6\%; $P=$ 0.17).

Finally, there was not any relationship between renal dysfunction and BKV viruria in this population. Only 1 patient had renal insufficiency, although it was present before $\mathrm{BKV}$ infection, and neither this patient nor the rest of the population developed further renal impairment. However, 
other types of immunocompromised populations, such as renal transplant recipients or AIDS patients, develop an increased rate of interstitial nephritis and renal failure associated with BKV infection [6].

Our study has some limitations. The relatively low number of patients prevented us from establishing a statistical relationship between the use of monoclonal antibodies and $\mathrm{BKV}$ reactivation and finding related clinical manifestations.

\section{Conclusion}

We observed that IBD patients have a high rate of BKV viruria and that it is more frequent in outpatients and in those not receiving ciprofloxacin. More studies are needed to determine the role of BKV in this population.

\section{Conflict of Interests}

The authors declare that there is no conflict of interests regarding the publication of this paper

\section{Authors' Contribution}

Virginia Flores and Belén Rodríguez-Sánchez have contributed equally to this study.

\section{Acknowledgments}

This study was funded by Fondo de Investigaciones Sanitarias (PI0690636), ISCIII, Ministerio de Sanidad y Consumo (Spanish Ministry of Health) and Fundación de Investigación Médica Mutua Madrileña, 2007-2010. The authors thank the patients for their cooperation, Dr. Leticia Holguera for helping with data recording, Dr. Juan Ledesma for helping with the PCR, and Dr. Y. L. Kwong (University Hospital of Hong Kong) for providing the plasmid standard pB-VP1. Jose M. Bellón (Fundación para la Investigación Biomédica del Hospital Gregorio Marañón, Madrid, Spain) assisted with the interpretation of the statistical results. The authors thank Tom O'Boyle for the review of the English usage.

\section{References}

[1] S. D. Gardner, A. M. Field, D. V. Coleman, and B. Hulme, "New human papovavirus (B.K.) isolated from urine after renal transplantation," The Lancet, vol. 1, no. 7712, pp. 1253-1257, 1971.

[2] H. H. Hirsch, D. C. Brennan, C. B. Drachenberg et al., "Polyomavirus-associated nephropathy in renal transplantation: interdisciplinary analyses and recommendations," Transplantation, vol. 79, no. 10, pp. 1277-1286, 2005.

[3] H. H. Hirsch, "BK virus: opportunity makes a pathogen," Clinical Infectious Diseases, vol. 41, no. 3, pp. 354-360, 2005.

[4] M. Jiang, J. R. Abend, S. F. Johnson, and M. J. Imperiale, "The role of polyomaviruses in human disease," Virology, vol. 384, no. 2, pp. 266-273, 2009.

[5] H. H. Hirsch and J. Steiger, "Polyomavirus BK," Lancet Infectious Diseases, vol. 3, no. 10, pp. 611-623, 2003.

[6] P. Comoli, S. Binggeli, F. Ginevri, and H. H. Hirsch, "Polyomavirus-associated nephropathy: update on BK virus-specific immunity," Transplant Infectious Disease, vol. 8, no. 2, pp. 86-94, 2006.

[7] O. Megged, J. Stein, D. Ben-Meir et al., "BK-virus-associated hemorrhagic cystitis in children after hematopoietic stem cell transplantation," Journal of Pediatric Hematology/Oncology, vol. 33, no. 3, pp. 190-193, 2011.

[8] L. Giuliani, C. Ronci, D. Bonifacio et al., "Detection of oncogenic DNA viruses in colorectal cancer," Anticancer Research, vol. 28, no. 2 B, pp. 1405-1410, 2008.

[9] G. Y. Kim, J. Peji, G. Nuovo, and F. Thomas, "BK virus colonic ulcerations," Clinical Gastroenterology and Hepatology, vol. 2, no. 2, pp. 175-177, 2004.

[10] R. F. Harvey and J. M. Bradshaw, "A simple index of Crohn'sdisease activity," The Lancet, vol. 1, no. 8167, p. 514, 1980.

[11] M. S. Silverberg, J. Satsangi, T. Ahmad et al., "Toward an integrated clinical, molecular and serological classification of inflammatory bowel disease: report of a working party of the 2005 montreal world congress of gastroenterology," Canadian Journal of Gastroenterology, vol. 19, supplement A, pp. 5-36, 2005.

[12] C. G. Fedele, M. Ciardi, S. Delia, J. M. Echevarria, and A. Tenorio, "Multiplex polymerase chain reaction for the simultaneous detection and typing of polyomavirus JC, BK and SV40 DNA in clinical samples," Journal of Virological Methods, vol. 82, no. 2, pp. 137-144, 1999.

[13] P. Muñoz, M. Fogeda, E. Bouza, E. Verde, J. Palomo, and R. Bañares, "Prevalence of BK virus replication among recipients of solid organ transplants," Clinical Infectious Diseases, vol. 41, pp. 1720-1725, 2005.

[14] B. Loeches, M. Valerio, M. Pérez et al., "BK virus in liver transplant recipients: a prospective study," Transplantation Proceedings, vol. 41, pp. 1033-1037, 2009, Erratum in Transplantation Proceedings, vol. 41, p. 2006, 2009.

[15] J. Ledesma, P. Muñoz, D. Garcia de Viedma et al., "BK virus infection in human immunodeficiency virus-infected patients," European Journal of Clinical Microbiology and Infectious Diseases, vol. 31, no. 7, pp. 1531-1535, 2011.

[16] A. Y. H. Leung, M. Chan, S. C. W. Tang, R. Liang, and Y. L. Kwong, "Real-time quantitative analysis of polyoma BK viremia and viruria in renal allograft recipients," Journal of Virological Methods, vol. 103, no. 1, pp. 51-56, 2002.

[17] A. Egli, L. Infanti, A. Dumoulin et al., "Prevalence of polyomavirus BK and JC infection and replication in 400 healthy blood donors," Journal of Infectious Diseases, vol. 199, no. 6, pp. 837-846, 2009.

[18] A. Bellizzi, V. Barucca, D. Fioriti et al., "Early years of biological agents therapy in Crohn's disease and risk of the human polyomavirus JC reactivation," Journal of Cellular Physiology, vol. 224, no. 2, pp. 316-326, 2010.

[19] S. A. Sadiq, L. M. Puccio, and E. W. A. Brydon, "JCV detection in multiple sclerosis patients treated with natalizumab," Journal of Neurology, vol. 257, no. 6, pp. 954-958, 2010.

[20] R. M. Lonergan, M. J. Carr, C. F. de Gascun et al., "Reactivation of BK polyomavirus in patients with multiple sclerosis receiving natalizumab therapy," Journal of NeuroVirology, vol. 15, no. 5-6, pp. 351-359, 2009.

[21] A. Y. H. Leung, M. T. L. Chan, K.-Y. Yuen et al., "Ciprofloxacin decreased polyoma BK virus load in patients who underwent allogeneic hematopoietic stem cell transplantation," Clinical Infectious Diseases, vol. 40, no. 4, pp. 528-537, 2005. 
[22] M. Koukoulaki, T. Apostolou, V. Hadjiconstantinou, and S. Drakopoulos, "Impact of prophylactic administration of ciprofloxacin on BK polyoma virus replication," Transplant Infectious Disease, vol. 10, no. 6, pp. 449-451, 2008.

[23] S. Gabardi, S. S. Waikar, S. Martin et al., "Evaluation of fluoroquinolones for the prevention of BK viremia after renal transplantation," Clinical Journal of the American Society of Nephrology, vol. 5, no. 7, pp. 1298-1304, 2010.

[24] S. H. Ali, A. Chandraker, and J. A. DeCaprio, "Inhibition of Simian virus 40 large $\mathrm{T}$ antigen helicase activity by fluoroquinolones," Antiviral Therapy, vol. 12, no. 1, pp. 1-6, 2007. 


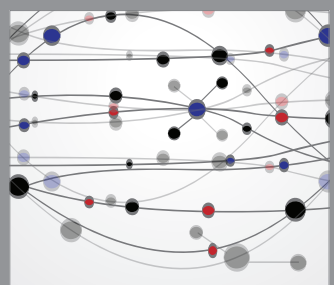

The Scientific World Journal
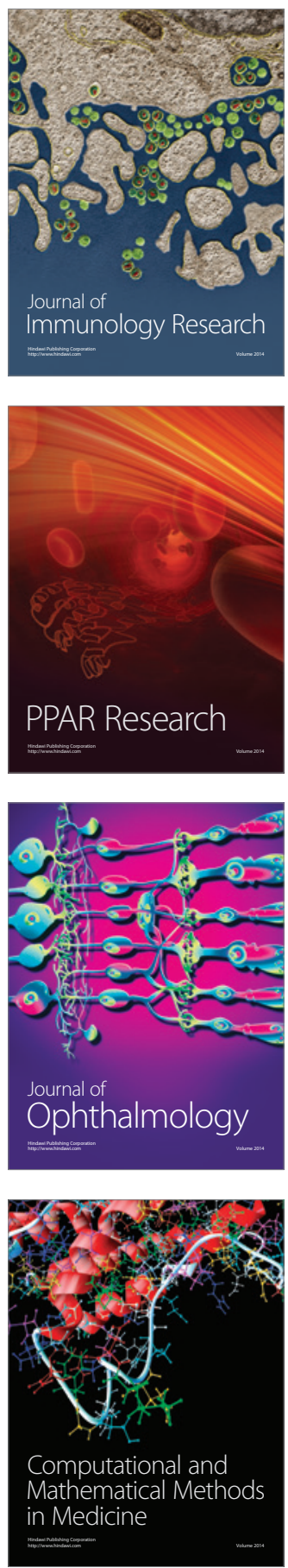

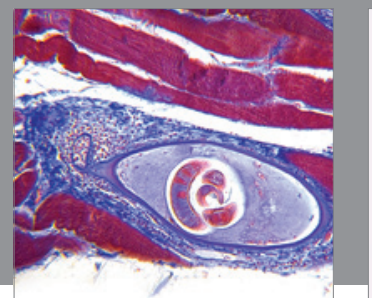

Gastroenterology

Research and Practice
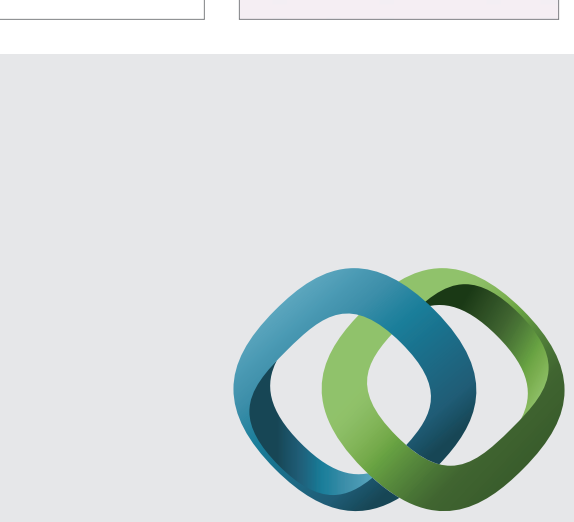

\section{Hindawi}

Submit your manuscripts at

http://www.hindawi.com
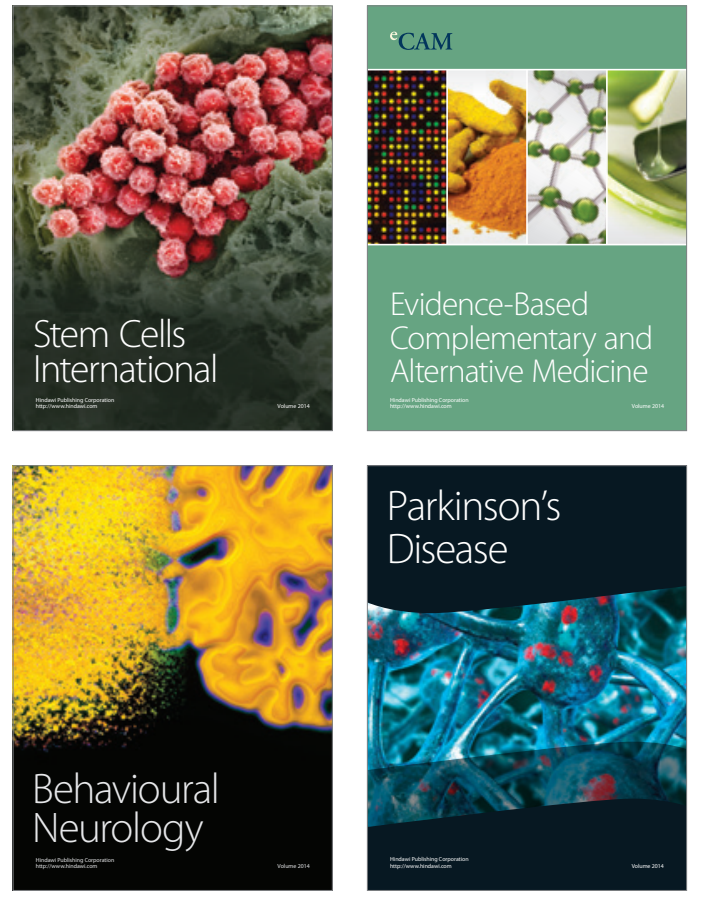
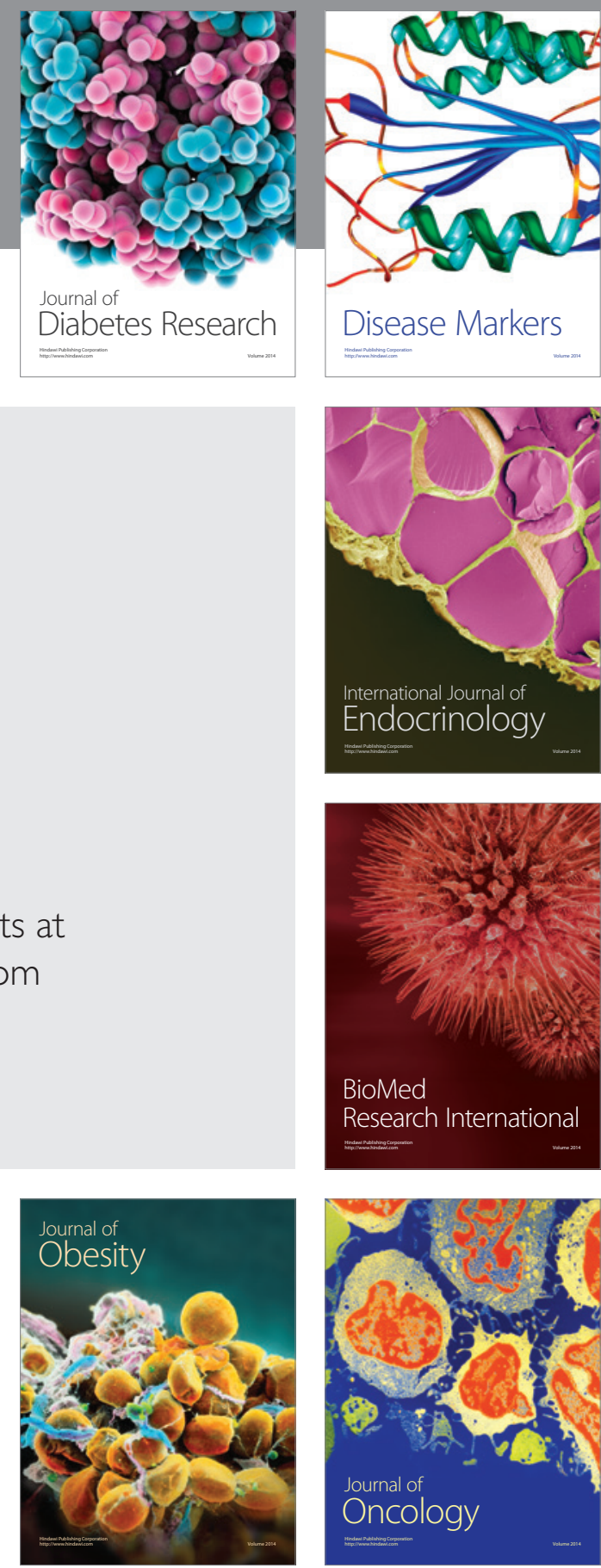

Disease Markers
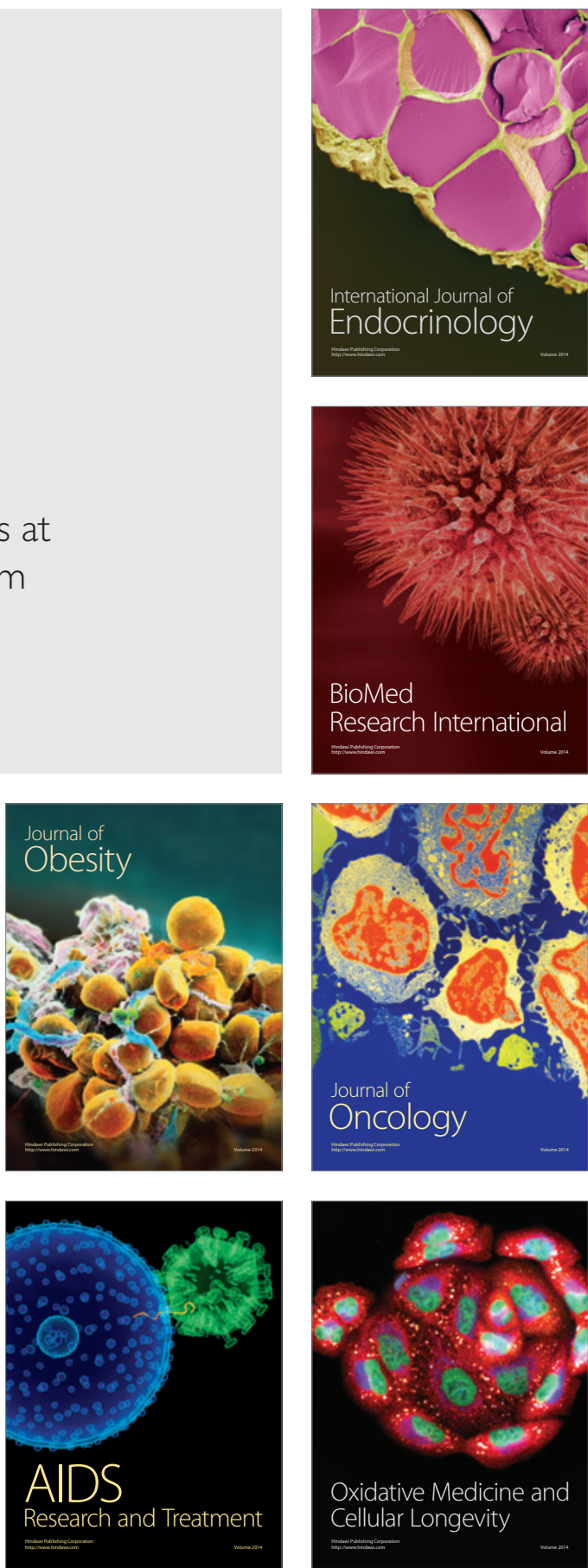